thấy rằng nhóm sử dụng Pregabalin kết hợp miếng dán Lidocain $5 \%$ có hiệu quả giảm đau nhiều hơn so với nhóm sử dụng lidocain đơn thuần. Kết quả này tương đồng với Wolff RF và cộng sự năm 201. ${ }^{5}$

Khô miệng là tác dụng phụ gặp nhiều nhất ở cả hai nhóm nghiên cứu và đối chứng với tỷ lệ lần lượt là 96,7\% và 93,3\%. Tác dụng phụ thường gặp thứ hai là chóng mặt chiếm tỷ lệ $55 \%$ trong nhóm nghiên cứu và $51,7 \%$ nhóm chứng.

\section{KẾT LUẬN VÀ KHUYẾN NGH!}

Cả hai nhóm dùng Pregabalin đơn thuần và Pregabalin kết hợp miếng dán Lidocain $5 \%$ đều có hiệu quả giảm đau, tuy nhiên nhóm dùng Pregabalin kết hợp miếng dán Lidocain $5 \%$ có hiệu quả giảm đau tốt hơn sau 2 tuần và 8 tuần điểu trị. Khuyến nghị sử dụng kết hợp Pregabalin cùng miếng dán Lidocain $5 \%$ để đem lại hiệu quả điều trị tốt nhất cho bệnh nhân.

\section{TÀI LIÊU THAM KHẢO}

1. Johnson RW, Dworkin RH. Treatment of herpes zoster and postherpetic neuralgia. Bmj. 2003;326(7392):748-750.

2. Yawn BP, Saddier $P$, Wollan PC, Sauver JLS, Kurland MJ, Sy LS. A population-based study of the incidence and complication rates of herpes zoster before zoster vaccine introduction. Elsevier; 2007:1341-1349.

3. Kawai K, Gebremeskel BG, Acosta CJ. Systematic review of incidence and complications of herpes zoster: towards a global perspective. BMJ open. 2014;4(6):e004833.

4. Marra F, Parhar K, Huang B, Vadlamudi N. Risk factors for herpes zoster infection: a metaanalysis. Oxford University Press US; 2020:ofaa005.

5. Wolff RF, Bala M, Westwood M, Kessels A, Kleijnen J. $5 \%$ lidocaine-medicated plaster vs other relevant interventions and placebo for post-herpetic neuralgia (PHN): a systematic review. Acta neurologica Scandinavica. 2011;123 (5):295-309.

\title{
ĐÁNH GIÁ MỐI TƯƠ'NG QUAN Bộ BA AFP, AFP-L3\%, PIVKA-II VỚI CÁC YẾU TỐ LÂM SÀNG, CẬN LÂM SÀNG TRÊN BÊ̂NH NHÂN VIÊM GAN C
}

\author{
Phạm Cẩm Phương ${ }^{1}$, Phạm Văn Thái ${ }^{1}$, Nguyễn Thuận Lọi ${ }^{1}$, \\ Nguyễn Văn Dũng ${ }^{2}$, Lê Thị Hồng Linh², Võ Thị Thúy Quỳnh', \\ Lê Thị Bích Ngọc ${ }^{1}$, Vũ Bình Thưr ${ }^{1}$ Vũ Thị Thu Hiền' và cộng sự

\section{SUMMARY \\ EVALUATION THE CORRELATION OF THE APE, AFP-L3, PIVKA-II WITH CLINICAL AND SUBCLINICAL FACTORS OF} \\ HEPATITIS C PATIENTS
}

\section{TÓM TẮT}

Mục tiêu: Mô tả một số đặc điểm lâm sàng và cận lâm sằng của nhóm bệnh nhẩn viêm gan $C$; đánh giá mối tương quan của bộ ba AFP, AFP - L3 với PIVKA-II với các đặc điểm bệnh nhân viêm gan $C$. Đối tượng và phướng pháp: Nghiên cứu mô tả tiến cứu trên 33 đối tượng viêm gan C. Kết quả: Bệnh nhân nam giới chiếm đa số, tỳ lệ nam/nữ là $2 / 1$, tuổi trung bình cả nam và nữ là $53, \bar{j}$ tuổi. Trong số các bênh nhân viêm gan $C$, nghiện rượu là đặc điểm có tỳ lệ cao nhất $39,4 \%$. Các triệu chứng lâm sàng thường gặp là chán ăn, mệt mỏi, chướng bụng. Các chỉ số cao hơn giá trị người bình thường là AST $173,5 \pm 449 \mathrm{U} / \mathrm{L}, \mathrm{ALT}$ $121,8 \pm 258,4 \mathrm{U} / \mathrm{L}$. Nhóm bệnh nhân có u, một trong ba chỉ số AFFP, AFP-L3, PIVKA-II vượt ngướng có tỷ lệ là $87,5 \%$, trong nhóm bệnh nhân không có u, cả ba chỉ số dưới ngưỡng là 22,2\%. Kết luận: Giá trị AFP, AFP-L3\% và PIVKA-II tăng cao trong đạ số bệnh nhân viêm gan $\mathrm{C}$ có xuất hiện khối u.

\footnotetext{
${ }^{1}$ Trung tâm Y học hạt nhân và Ung bướu, Bệnh viện Bach Mai

2Trung tâm Bệnh nhiệt đới, Bệnh viện Bạch Mai

Chịu trách nhiệm chính: Phạm Cẩm Phương

Email: phamcamphuong@gmail.com

Ngày nhận bài: 9.8.2021

Ngày phản biện khoa học: 4.10.2021

Ngày duyệt bài: 14.10.2021
}

Aims: To describe some clinical and subclinical characteristics of hepatitis $C$ patients; evaluated the correlation of AFP, AFP - L3 and PIVKA-II with the characteristics of hepatitis $C$ patients. Patients and methods: A prospective descriptive study on 33 hepatitis $C$ patients. Results: Male patients accounted for the majority, the male/female ratio was $2 / 1$, the average age of both men and women was 53.7 years old. Among hepatitis $C$ patients, alcoholism was the highest rate of $39.4 \%$. Common clinical symptoms were anorexia, fatigue, and abdominal distension. Indicators higher than normal values were AST $173.5 \pm 449 \mathrm{U} / \mathrm{L}$, ALT $121.8 \pm 258.4 \mathrm{U} / \mathrm{L}$. In the group of patients with tumor, one of the three markers AFP, AFP-L3, PIVKA-II exceeded the threshold rate was $87.5 \%$, in the group of patients without tumor, all three indexes below the threshold was $22.2 \%$. Conclusions: AFP, AFP-L3and PIVKA-II values were elevated in the majority of hepatitis $C$ patients with tumors.

\section{I. ĐẶT VẤN ĐỀ}

Bệnh viêm gan $C$ đã được xác định trong thời gian dài vừa qua và cho đển nay virut viêm gan 
C vẫn đang là một trong những nguyên nhân hàng đầu gây viêm gan mạn tính, xơ gan và dẫn đến ung thư tế bào gan. Theo Tổ chức $Y$ tế Thế giới (WHO), trên toàn cầu có khoảng 130 - 170 triệu người nhiễm virus viêm gan $\mathrm{C}(\mathrm{HCV})$ và theo ước tính khoảng $80 \%$ các trường hợp nhiễm HCV sẽ tiến triển thành viêm gan mạn tính. Tại Việt Nam, gần một triệu người đang sống chung với viêm gan C [1]. Một nghiên cứu cho thấy gần $90 \%$ người ung thư gan đã hoặc đang nhiễm virus viêm gan $B, C$ hoặc cả hai loại. Trong quá trình tiến triển của bệnh viêm gan $C$ mạn tính dẫn đến tình trạng xơ hóa gan là một trong những yếu tố nguy hiểm gây bệnh ung thư gan. Cho đến nay sinh thiết gan vẫn được coi là tiêu chuẩn vàng để đánh giá tình trạng xơ hóa gan, ung thư gan [2], [3]. Tuy nhiên, đây là một thủ thuật xâm lấn nên có một số hạn chế như gây đau, có một số tai biến như chảy máu.

Trong chẩn đoán ung thư biểu mô tế bào gan thì alpha feto protein (AFP) được coi là một chất chỉ dấu ung thư và được ứng dụng trong lâm sàng nhiêu nhất. Ở người lớn khỏe mạnh (phụ nữ không mang thai), mức độ AFP huyết thanh chỉ từ $0-10 \mathrm{ng} / \mathrm{ml}$. Tuy nhiên, ở bệnh nhân xơ gan nồng độ AFP có thể tăng lên đến $40 \%$. Bệnh nhân ung thư biểu mô tế bào gan có thể có nồng độ AFP dao động từ ngưỡng bình thường cho đến > $100000 \mathrm{ng} / \mathrm{mL}$ [4]. AFP-L3 là dạng đồng phân của AFP có đặc tính ái lực cao với Lens culinaris agglutinin (LCA). AFP-L3 tăng trong huyết thanh đặc hiệu cao cho ung thư biểu mô tế bào gan. PIVKA-II là một dạng bất thường được tạo ra bởi sự thiếu Vitamin $\mathrm{K}$ của prothrombin, một yếu tố đông máu được sản xuất bởi gan, nồng độ PIVKA-II bình thường thấp hơn $40 \mathrm{mAU} / \mathrm{mL}$. Nhiều nghiên cứu trên thế giới cho thấy PIVKA-II có độ nhạy cao hơn và có giá trị chẩn đoán độc lập so với chỉ điểm AFP trong việc chẩn đoán sớm ung thư biểu mô tế bào gan. Khi kết hợp 3 chất chỉ điểm PIVKA-II với AFP và AFP-L3 sẽ làm tăng tỷ lệ phát hiện ung thư biểu mô tế bào gan [5]. Ung thư gan có tỷ lệ sống sót sau 5 năm trên $70 \%$ nếu bệnh nhân được chẩn đoán ở giai đoan sớm, tuy nhiên để chẩn đoán sớm ung thư biểu mô tế bào gan là phức tạp bởi sự cùng tồn tại của viêm gan mạn hoặc xơ gan [6]. Do vậy, việc bổ sung thêm các dấu ấn sinh học để chẩn đoán, phát hiện sớm viêm gan virus rất quang trọng cho việc phòng ngừa, ngăn chặn tiến triển ung thư gan.

Do đó nghiên cứu này với mục tiêu: Mô tả một số đặc điểm lâm sàng và cận lâm sàng của nhóm bệnh nhân viêm gan C; đánh giá mối tương quan của bọ ba AFP, AFP-L3 và PIVKA-II với các đặc điểm bệnh nhân viêm gan $C$.

\section{II. ĐỐI TƯỢNG VÀ PHƯƠNG PHÁP NGHIÊN CứU}

Đối tượng nghiên cứu: Các bệnh nhân được chẩn đoán xác định là viêm gan $\mathrm{C}$ có $\mathrm{HCV}$ RNA dương tính tại Bệnh viện Bạch Mai và một số bệnh viện trong khu vực Hà Nội từ tháng 10 năm 2019 đến tháng 3 năm 2021 được làm các xét nghiệm bộ ba AFP, AFP-L3, PIVKA-II.

Phướng pháp nghiên cứu: Đề tài được tiến hành theo phương pháp mô tả tiến cứu

\section{KẾT QUẢ NGHIÊN CỨU}

Bảng 2. Đặc điểm tuổi của đôi tượng nghiên cứu

\begin{tabular}{|c|c|c|}
\hline Nhóm tuối & Số lượng & Tỷ lệ \% \\
\hline$\leq 40$ tuối & 6 & 18,2 \\
\hline $41-70$ tuối & 22 & 66,7 \\
\hline$>70$ tuối & 5 & 15,1 \\
\hline Tống & 33 & 100 \\
\hline \multicolumn{2}{|c|}{ Tuối trung bình: $53,7 \pm 13,6$} \\
\hline
\end{tabular}

Nhận xét: Nhóm tuổi có tỷ lệ cao nhất là nhóm 41-70 tuổi. Tuổi trung bình của đối tượng xơ gan là 53,7 , trong đó bệnh nhân trẻ nhất là 30 tuổi, già nhất là 90 tuổi.

Bảng 2. Đặc điểm giới của đôi tượng nghiên cứu

\begin{tabular}{|c|c|c|}
\hline & Số lượng & Tỷ lệ \% \\
\hline Nam & 22 & 66,7 \\
\hline Nữ & 11 & 33,3 \\
\hline Tống & $\mathbf{3 3}$ & $\mathbf{1 0 0}$ \\
\hline
\end{tabular}

Nhận xét: Viêm gan C gặp thường gặp ơ bệnh nhân nam nhiều hơn bệnh nhân nữ. Tỉ lệ nam/nữ là $2 / 1$.

Bảng 3. Đặc điểm bênh nhân viêm gan $C$

\begin{tabular}{|c|c|c|c|c|c|}
\hline & $\begin{array}{c}\text { Viêm gan B } \\
(\mathbf{n}, \mathbf{\%})\end{array}$ & $\begin{array}{c}\text { Rượu } \\
(\mathbf{n}, \mathbf{\%})\end{array}$ & $\begin{array}{c}\text { Rượu + VGB } \\
(\mathbf{n}, \mathbf{\%})\end{array}$ & $\begin{array}{c}\text { Xo gan } \\
(\mathbf{n}, \mathbf{\%})\end{array}$ & $\begin{array}{c}\text { Xo gan+VGB } \\
(\mathbf{n}, \mathbf{\%})\end{array}$ \\
\hline Có & $7(21,2 \%)$ & $13(39,4 \%)$ & $4(12,1 \%)$ & $5(15,2 \%)$ & $2(6,1 \%)$ \\
\hline Không & $26(78,8 \%)$ & $20(60,6 \%)$ & $29(87,9 \%)$ & $28(84,8 \%)$ & $31(93,9 \%)$ \\
\hline Tổng & $\mathbf{3 3 ( 1 0 0 \% )}$ & $\mathbf{3 3 ( 1 0 0 \% )}$ & $\mathbf{3 3 ( 1 0 0 \% )}$ & $\mathbf{3 3 ( 1 0 0 \% )}$ & $\mathbf{3 3}(\mathbf{1 0 0 \% )}$ \\
\hline
\end{tabular}

Nhận xét: Trong số 33 bệnh nhân viêm gan $C$, nghiện rượu là đặc điếm có tỷ lệ cao nhất $39,4 \%$, xơ gan kết hợp viêm gan B có tỷ lệ thấp nhất 6,1\%. 
Bảng 4. Đặc điểm lâm sàng của đôî́ tượng nghiên cứu

\begin{tabular}{|c|c|c|}
\hline Đặc điếm & Số lượng & Tỷ lệ \% \\
\hline Chán ăn & 9 & 27,3 \\
\hline Mệt mỏi & 12 & 36,4 \\
\hline Buồn nôn & 1 & 3 \\
\hline Gầy sút cân & 3 & 9,1 \\
\hline Đau bụng hạ sườn phải & 5 & 15,2 \\
\hline Chướng bụng & 7 & 21,2 \\
\hline Vàng da, vàng mắt & 5 & 15,2 \\
\hline Ngứa & 2 & 6,1 \\
\hline Rối loạn tiêu hoá & 4 & 12,1 \\
\hline Gan to & 0 & 0 \\
\hline Tuần hoàn bàng hệ & 6 & 6,1 \\
\hline Phù & 2 & 18,2 \\
\hline HC vàng da & 2 & 6,1 \\
\hline Lách to & 1 & 3 \\
\hline Cố trướng & 3 & 9,1 \\
\hline
\end{tabular}

Nhận xét: Các triệu chứng lâm sàng thường gặp là chán ăn, mệt mỏi, chướng bụng. Các triệu chứng lâm sàng ít gặp là buồn nôn, gan to, lách to.

Bảng 5. Đặc điểm cận lâm sàng của đôi tượng nghiên cứu

\begin{tabular}{|c|c|}
\hline Đặc điểm huyết đồ & Giá trị trung bình \\
\hline Hồng câuu (T/L) & $4,5 \pm 0,9$ \\
\hline Huyết sắc tố $(\mathrm{g} / \mathrm{L})$ & $134,1 \pm 24,5$ \\
\hline Bạch câu (G/L) & $12,8 \pm 39,2$ \\
\hline Tiều cầu (G/L) & $183,6 \pm 89,6$ \\
\hline Chỉ số đông máu & Giá trị trung bình \\
\hline PT (\%) & $87,2 \pm 24,8$ \\
\hline INR & $1,1 \pm 0,2$ \\
\hline Fibrinogen $(\mathrm{g} / \mathrm{l})$ & $3,1 \pm 0,8$ \\
\hline APTT (s) & $30,6 \pm 8,3$ \\
\hline Chỉ số sinh hoá & Giá trị trung bình \\
\hline Glucose $(\mathrm{mmol} / \mathrm{L})$ & $8,2 \pm 13,2$ \\
\hline Ure (mmol/L) & $4,8 \pm 1,3$ \\
\hline Creatinin $(\mu \mathrm{mol} / \mathrm{L})$ & $73,6 \pm 18,7$ \\
\hline AST $(\mathrm{U} / \mathrm{L})$ & $173,5 \pm 449,1$ \\
\hline $\operatorname{ALT}(\mathrm{U} / \mathrm{L})$ & $121,8 \pm 258,4$ \\
\hline $\begin{array}{l}\text { Bilirubin toàn phần } \\
(\mu \mathrm{mol} / \mathrm{L})\end{array}$ & $46,6 \pm 75,2$ \\
\hline Albumin $(\mathrm{g} / \mathrm{L})$ & $34,4 \pm 10,7$ \\
\hline HCV-RNA (cp/mL) & $2 \times 10^{6} \pm 2,4 \times 10^{6}$ \\
\hline
\end{tabular}

Nhân xét: Các chỉ số cao hơn giá trị người bình thường là AST: $173,5 \pm 449 \mathrm{U} / \mathrm{L}, \mathrm{ALT}$ : $121,8 \pm 258,4 \mathrm{U} / \mathrm{L}$, tải lượng HCV-RNA là $2 \times 10^{6}$ $\pm 2,4 \times 10^{6} \mathrm{cp} / \mathrm{mL}$.

Bảng 6. Đặc điểm AFP, AFP-L3\%, PIVKA-II theo kêt quả siêu âm

\begin{tabular}{|c|c|c|c|}
\hline & $\begin{array}{c}\text { Siêu âm } \\
\text { có u }\end{array}$ & $\begin{array}{c}\text { Siêu âm } \\
\text { không có u }\end{array}$ & Tổng \\
\hline Bộ ba (+) & $21(87,5 \%)$ & $3(12,5 \%)$ & $24(100 \%)$ \\
\hline Bộ ba $(-)$ & $7(77,8 \%)$ & $2(22,2 \%)$ & $9(100 \%)$ \\
\hline Tống & $\mathbf{2 8}$ & $\mathbf{5}$ & $\mathbf{3 3}$ \\
\hline
\end{tabular}

\section{Pearson \\ Chi-square \\ 0,488}

Nhận xét: Nhóm bênh nhân có u tỷ lẹ bộ ba AFP, AFP-L3\% và PIVKA-II $(+)$ là $87,5 \%$, trong nhóm bệnh nhân không có u, bộ ba AFP, AFPL3\% và PIVKA-II (-) 22,2\%. (trong đó Bộ ba AFP, AFP-L3\% và PIVKA-II (+) là một trong các giá trị của chúng vượt quá ngưỡng giá trị bình thường).

\section{BÀN LUẬN}

Trong nghiên cứu của chúng tôi, tỷ lệ bệnh nhân nam giới chiếm đa số là $66,7 \%$, nữ giới chiếm tỷ lệ là $33,3 \%$, tỷ lệ nữ/nam là $2 / 1$, tuổi trung bình cả nam và nữ là 56 tuổi, trẻ nhất là 26 tuổi, già nhất là 83 tuổi. Kết quả này tương đương với kết quả nghiên cứu của đây có thể là tỷ lệ tuổi mắc các bênh nền và việc sử dụng rượu là phố biến ở người Việt Nam đặc biệt là nam giới có thói quen uống rượu. Trong số 33 bệnh nhân viêm gan $C$, nghiện rượu là đặc điểm có tỷ lệ cao nhất $39,4 \%$. Ngoài ra cũng phải kể đến tỷ lệ mắc viêm gan $B$ ở Việt nam, đặc biệt ở các tình miên núi phía Bắc, vì vậy viêm gan $B$ kết hợp cùng với viêm gan $C$ cũng là một nhóm đối tượng có tỳ trọng lớn trong nghiên cứu này của chúng tôi.

Các biểu hiện được ghi nhận trong nghiên cứu này, hay gặp gồm mệt mỏi $(36,4 \%)$, chán ăn $(27,3 \%)$, chướng bụng $(21,2 \%)$ cũng khá tương đồng với các đặc điểm lâm sàng của người bệnh viêm gan $C$ virus đã được mô tả trên thế giới. Tuy nhiên, một số kết quả nghiên cứu cũng ghi nhận bệnh này khó phát hiện trên lâm sàng, việc phát hiên chủ yếu thông qua việc khám sức khỏe định kỳ hoặc do các trường hợp ngấu nhiên.

Về cận lâm sàng, giá trị trung bình của các chỉ số huyết học không có sự khác biệt với các chỉ số của người bình thường, chỉ riêng AST và ALT có thay đổi bất thường với AST 173,5 \pm 449 $\mathrm{U} / \mathrm{L}$, và $A L T 121,8 \pm 258,4 \mathrm{U} / \mathrm{L}$. Đây cũng có thể là một trong các chính khiến bệnh nhân đi khám bệnh và tầm soát nguyên nhẩn gây bệnh. Tải lượng HCV-RNA là $2 \times 10^{6} \pm 2,4 \times 10^{6} \mathrm{cp} / \mathrm{mL}$

Trong nghiên cứu của Ngô Thị Thanh Quýt, AST và ALT thay đổi, lần lượt là $68,9 \pm 50,2$ và $59,4 \pm 44,7[7]$. Trong nghiên cứu của Lâm Hoàng Cát Tiên, AST tăng cũng là rối loạn cận lâm sàng thường gặp, chiếm tỷ lệ $75 \%$ [8]. So sánh kết quả nghiên cứu này và các nghiên cứu khác đều cho thây sự thay đổi giá trị AST và ALT là biểu hiện cận lâm sàng thường gặp sớm trong nhóm bệnh nhân viên gan $C$ virus.

Nồng độ trung bình AFP, AFP-L3\% và PIVKAII đã cho thấy rằng sẽ tăng cao trong các trường hợp kích thước khối u lớn, bệnh nhân ung thư 
giai đoạn muộn, tuy nhiên với viêm gan $C$ thì chưa có nhiều nghiên cứu trong nước. Trong nghiên cứu của chúng tôi, nồng độ trung bình của một trong ba chỉ số AFP, AFP-L3\% và PIVKA-II có giá trị tăng cao vượt ngưỡng cut off ở nhóm bệnh nhân có khối u là $87,5 \%$, và ngược lại trong nhóm bệnh nhân không có u thì cả ba chỉ số này đều dưới ngưỡng cut off là $22 \%$. Kết quả này tương tự như nghiên cứu trên thế giới, khi họ xem bộ ba AFP, AFP-L3\% và PIVKA-II là chỉ dấu chẩn đoán sớm ung thư ở các bệnh nhân viêm gan $C$ virus [9].

\section{KẾT LUÂN}

Qua nghiên cứu trên 33 bệnh nhân viêm gan C tại Trung tâm $\mathrm{Y}$ học hạt nhân và Ung bướu, Bệnh viện Bạch Mai từ tháng 10/2019 đến tháng 3/2021. Cho thấy:

- Bệnh nhân nam giới chiếm đa số là 66,7\%, nữ giới chiếm tỷ lệ là $33,3 \%$, tỷ lệ nữ/nam là $2 / 1$, tuổi trung bình cả nam và nữ là 53,7 tuổi, trẻ nhất là 26 tuổi, già nhất là 83 tuổi.

- Nghiện rượu là đặc điểm có tỷ lệ cao nhất $39,4 \%$, xở gan kết hợp viêm gan $B$ có tỷ lệ thấp nhất $6,1 \%$.

- Các triệu chứng lâm sàng thường gặp là chán ăn, mệt mỏi, chướng bụng. Các triệu chứng lâm sàng ít gặp là buồn nôn, gan to, lách to.

- Các chỉ số cao hơn giá trị người bình thường là AST 173,5 $\pm 449 \mathrm{U} / \mathrm{L}, \mathrm{ALT} 121,8 \pm 258,4 \mathrm{U} / \mathrm{L}$, tải lượng HCV-RNA là $2 \times 10^{6} \pm 2,4 \times 10^{6} \mathrm{cp} / \mathrm{mL}$.

- Nhóm bệnh nhân có u, một trong ba chỉ số AFP, AFP-L3\% và PIVKA-II vượt ngưỡng có tỷ lệ là 87,5\%, trong nhóm bệnh nhân không có u, cả ba chỉ số dưới ngưỡng là $22,2 \%$

\section{TÀI LIÊU THAM KHẢO}

1. The Washington manual of medical therapeutics 33nd edition. Hyuna Sung PhD Jacques Ferlay MSc, M.R.L.S.M.M.L.M.I.S.M., et al (2021) Global cancer statistics 2020: GLOBOCAN estimates of incidence and mortality worldwide for 36 cancers in 185 countries. CA: a cancer journal for clinicians. U'HO

2. Lefkowitch, J.H. (2007). Liver Biopsy Assessment in Chronic Hepatitis. Archives of Medical Research. 38(6), 634-643.

3. Rockey, D.C., Caldwell S.H., Goodman Z.D., et al. (2009). Liver biopsy. Hepatology. 49(3), 1017-44

4. Ricco G et al. (2018). Impact of etiology of chronic liver disease on hepatocellular carcinoma biomarkers. Cancer Biomark; 21(3):603-612

5. Lim T.S., D.Y. Kim, K.-H. Han, et al (2016). Combined use of AFP, PIVKA-II, and AFP-L3 as tumor markers enhances diagnostic accuracy for hepatocellular carcinoma in cirrhotic patients. Scandinavian journal of gastroenterology, 51(3), 344-353.

6. Hann H.-W., D. Li, H. Yamada, et al (2014), Usefulness of highly sensitive AFP-L3 and DCP in surveillance for hepatocellular carcinoma in patients with a normal Alpha-Fetoprotein. J Med Microb Diagn, 3(1), 1-6.

7. Ngô Thi Thanh Quýt, Nguyễn Phương, Lê Thành Lý, Bùi Hữu Hoàng (2010), "Chẩn đoán mức đô xơ hóa gan bằng phương pháp đo độ đàn hồi gan trên bệnh nhân bệnh gan mạn", Tap chí Y Hoc Thành phổ Hồ Chí Minh, 14(1), tr.161-166.

8. Lẩm Hoàng Cát Tiên (2005), Khảo sát giá trị của phương pháp chẩn đoán khống xâm lấn trong xơ gan còn bù, Luân văn bác sĩ nội trú, Đại học Y Dược TP.Hồ Chí Minh.

9. Ivan G, Antonio B, Riccardo S. Diagnostic Accuracy of PIVKA-II, Alpha-Fetoprotein and a Combination of both in Diagnosis of Hepatocellular Carcinoma in Patients Affected by Chronic HCV Infection. In Vivo July 2017, 31 (4) 695-700

\title{
TÌNH TRANG DINH DƯỡ'NG VÀ ĐẶC ĐIỂM THÀNH PHẦN CƠ THỂ CỦA PHỤ NỮ 15 - 35 TUỔI TẠI HUYÊ̂N MƯỜNG LA, TỈNH SƠN LA NĂM 2018
}

\author{
Nguyễn Thúy Anh ${ }^{1}$, Nguyễn Song Tú ${ }^{1}$, \\ Nguyễn Hồng Trường ${ }^{1}$, Hoàng Nguyễn Phương Linh ${ }^{1}$
}

\section{TÓM TẮT}

Nghiên cứu được thực hiện nhằm đánh giá tình trang dinh dưỡng (TTDD) và đăc điểm thành phần cơ thể của phu nữ từ 15 đến 35 tuổi tại 5 xã nghèo của huyện Mường La, tỉnh Sơn La. Kết quả nghiên cứu cho

${ }^{1}$ Viện Dinh dưỡng Quốc gia

Chịu trách nhiệm chính: Nguyễn Thúy Anh Email: nguyenthuyanh@dinhduong.org.vn Ngày nhận bài: 6.8.2021

Ngày phản biên khoa hoc: 1.10 .2021

Ngày duyệt bài: 11.10.2021 thây cân nặng trung bình là 48,5 $\pm 6,5 \mathrm{~kg}$, chiêu cao trung bình là $151,8 \pm 5,3 \mathrm{~cm}$ và chỉ số khối cơ thể (BMI) trung bình là $21,0 \pm 2,4 \mathrm{~kg} / \mathrm{m}^{2}$. Tỷ lệ thiếu năng lượng trường diễn (CED) nhóm 20-35 tuổi là 8,9\% trong đó tỷ lệ SDD thấp còi và gâyy còm ở nhóm 15-19 tuổi lần lướt là $40 \%$ và $5,6 \%$. Cân năng, chiều cao và BMI trung bình giữa 4 nhóm tuổi của ĐTNC có sư khác biệt có YNTK $(p<0,001)$. Phần trăm mõ cơ thể $(\% B F)$ và khối lương mõ (FM) ở ĐTNC có sư thay đổi tăng dần theo lớp tuổi tăng dần, chỉ số \%BF và FM ở ĐTNC giữa các nhóm 15-19 và 30-35 khác biêt có YNTK vớl các nhóm tuổi còn lại $(p<0,05)$. Khối lượng cơ ước tính (PMM), khối lượng không mơ (FFM) ở ĐTNC cũng 